\title{
Serrated plastic flow during nanoindentation in Nd-based bulk metallic glasses
}

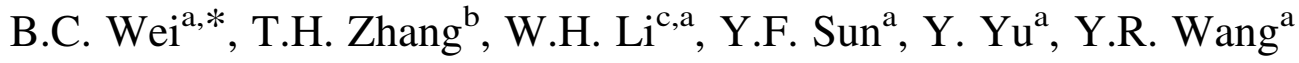 \\ ${ }^{a}$ National Microgravity Laboratory, Institute of Mechanics, Chinese Academy of Science, Beijing 100080, China \\ ${ }^{\mathrm{b}}$ State Key Laboratory of Nonlinear Mechanics (LNM), Institute of Mechanics, Chinese Academy of Sciences, Beijing 100080, China \\ ${ }^{\mathrm{c}}$ Institute of Materials, Shanghai University, Shanghai 200072, China
}

Available online 18 May 2004

\begin{abstract}
The microstructure of $\mathrm{Nd}_{60} \mathrm{Al}_{10} \mathrm{Ni}_{10} \mathrm{Cu}_{20-x} \mathrm{Fe}_{x}(x=0,5,7,10,15,20)$ alloys can change from homogeneous phase to a composite structure consisting of amorphous phase plus clusters or nanocrystals by adjusting the Fe content. The effect of microstructure on the plastic deformation behavior in this alloy system is studied by using nanoindentation. The alloys with homogeneous amorphous structure exhibit pronounced flow serrations during the loading process of nanoindentation. The addition of Fe changes the plastic deformation behavior remarkablely. No flow serration is observed in the alloys with high Fe content for the indentation depth of $500 \mathrm{~nm}$. The mechanism for the change of plastic serrated flow behavior is discussed.
\end{abstract}

(C) 2004 Elsevier Ltd. All rights reserved.

Keywords: A. Composites; B. Glasses, metallic; B. Mechanical properties at ambient temperature

\section{Introduction}

Bulk metallic glasses have attracted a great attention on fundamental science and practical applications due to their promising mechanical properties. However, in the area of structural applications, they are often limited by the lack of any significant plastic deformation at room temperature. Extensive research efforts have revealed that the limited room temperature ductility is due to a catastrophic failure resulting from shear localization, which is considered to be the primary plastic deformation mechanism in metallic glasses [1-7]. Recently, nanoindentation has been proposed as a method for the study of plastic deformation behaviors and serrated flow in BMGs [7-10]. Nanoindentation tests allow considerably larger plastic deformation to be accumulated in these quasi-brittle materials in a localized area around the indented regions. Nanoindentation behavior of $\mathrm{Zr}$-, Pd- and La-based BMGs was reported in detail. Serrated flow phenomenon during nanoindentation was already found at low strain rates [7-10]. In this work, the plastic deformation in $\mathrm{Nd}_{60} \mathrm{Al}_{10} \mathrm{Ni}_{10} \mathrm{Cu}_{20-x} \mathrm{Fe}_{x}(x=0,5,7$, $10,15,20)$ was studied by using nanoindentation

\footnotetext{
* Corresponding author. Tel.: + 86-10-62614945; fax: +86-1062615524.

E-mail address: weibc@imech.ac.cn (B.C. Wei).
}

experiments and atomic force microscopy. The effect of the microstructure on the serrated flow behavior is studied in this alloy system.

\section{Experimental}

Ingots of $\mathrm{Nd}_{60} \mathrm{Al}_{10} \mathrm{Ni}_{10} \mathrm{Cu}_{20-x} \mathrm{Fe}_{x}(x=0,5,7,10,15$, 20) were prepared by arc-melting a mixture of the pure elements $\mathrm{Nd}, \mathrm{Al}, \mathrm{Ni}, \mathrm{Cu}$ and $\mathrm{Fe}$ with a purity of at least 99.9\% in titanium-gettered argon atmosphere. Cylindrical specimens of $3 \mathrm{~mm}$ in diameter and $70 \mathrm{~mm}$ in length were prepared from the pre-alloyed ingots by suction casting into a copper mold. The structure of the samples was characterized by X-ray diffraction (XRD) using $\mathrm{Cu} \mathrm{K} \mathrm{K}_{\alpha}$ radiation. Thermal analysis was performed with a Perkin-Elmer DSC 7 differential scanning calorimeter under argon atmosphere. Microstructure of the samples with different Fe contents was examined using a JEM-2010 high-resolution electron microscope operated at $200 \mathrm{kV}$. The films were ion-milled in a liquid nitrogen specimen cooling stage. Nanoindentation tests were conducted using a MTS Nano Indenter ${ }^{\circledR}$ XP with a Berkovich diamond tip. Hardness and elastic modulus were measured using the continuous stiffness option, which yields elastic modulus and hardness as a function of indentation depth. A fused silica was used as a standard sample for the initial 
calibration. In the present study, a typical indentation experiment consists of seven subsequent steps: approaching the surface; determining the contact point; loading to peak load; holding the tip for $10 \mathrm{~s}$ at the peak load; unloading $90 \%$ of peak load; holding the tip for $100 \mathrm{~s}$ at $10 \%$ of the peak load for thermal drift correction; and finally unloading completely. The experimental parameters were chosen as follows: strain rate, $0.05 \mathrm{~s}^{-1}$; allowable drift rate, $0.05 \mathrm{~nm} / \mathrm{s}$; depth limit, $1.0 \mu \mathrm{m}$. The hardness and elastic modulus were obtained from the curves using Oliver-Pharr method [11]. Four types of experiments, hardness test at a depth, hardness test at a constant loading rate $(0.075 \mathrm{mN} / \mathrm{s})$, continuous stiffness test at a depth, continuous stiffness at a constant displacement rate, were performed at different loads and depths. Six indentations were made for each test on each specimen. All tests were carried out at $23{ }^{\circ} \mathrm{C}$. Indents surface observation was performed by a POLYVAR MET $^{\circledR}$ optical microscope, and atomic force microscopy (AFM AutoProbe CP Research Scanning Probe Microscope). The uniaxial compression tests on cylindrical samples of $3 \mathrm{~mm}$ in diameter and $5.8 \mathrm{~mm}$ in length were performed in an Instron-type testing machine at room temperature. The cross-head was moved at a constant speed with an initial strain rate of $1.4 \times 10^{-4} \mathrm{~s}^{-1}$. A JSM-6460 scanning electron microscope (SEM) was used for the analysis of the fracture feature.

\section{Results and discussion}

The XRD results obtained from the as-cast $\mathrm{Nd}_{60} \mathrm{Al}_{10}$ $\mathrm{Ni}_{10} \mathrm{Cu}_{20-x} \mathrm{Fe}_{x}(0 \leq x \leq 20)$ samples are presented in Fig. 1. All as-cast cylinders exhibit a spectrum typical for amorphous phase without obvious crystalline reflection peaks within the resolution limit of the XRD. However, the samples with higher $\mathrm{Fe}$ content exhibit a more obvious broad peak at the $2 \theta$ value of about $56^{\circ}$. This suggests that the substitute of $\mathrm{Cu}$ by $\mathrm{Fe}$ changes the short-range ordered structure in the $\mathrm{Nd}_{60} \mathrm{Al}_{10} \mathrm{Ni}_{10} \mathrm{Cu}_{20}$ alloy. Fig. 2

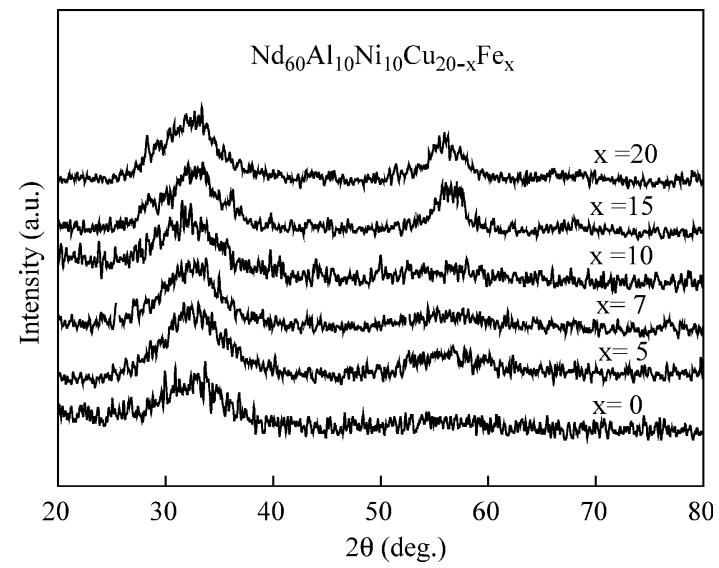

Fig. 1. XRD patterns for the as-cast $\mathrm{Nd}_{60} \mathrm{Al}_{10} \mathrm{Ni}_{10} \mathrm{Cu}_{20-x} \mathrm{Fe}_{x}(x=0,5,7$, $10,15,20)$ alloys.

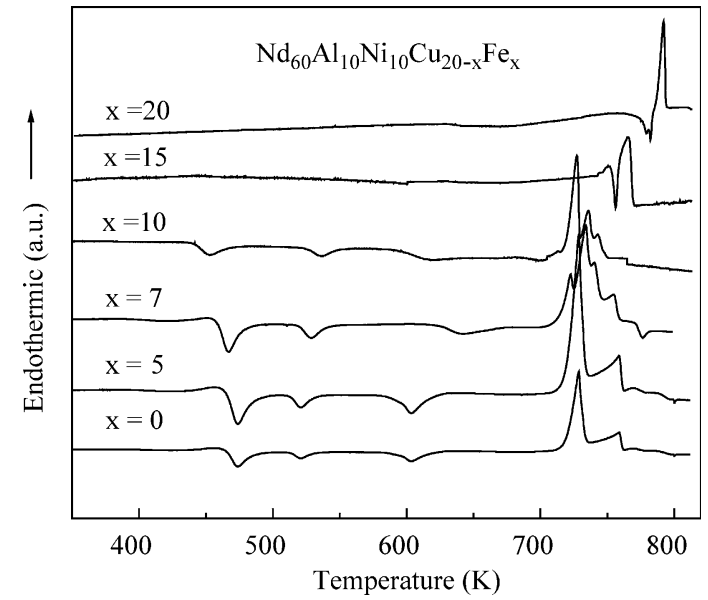

Fig. 2. DSC curves of $\mathrm{Nd}_{60} \mathrm{Al}_{10} \mathrm{Ni}_{10} \mathrm{Cu}_{20-x} \mathrm{Fe}_{x}(x=0,5,7,10,15,20)$ alloys at a heating rate of $20 \mathrm{~K} / \mathrm{min}$.

exhibits the DSC traces of the $\mathrm{Nd}_{60} \mathrm{Al}_{10} \mathrm{Ni}_{10} \mathrm{Cu}_{20-} \mathrm{Fe}_{x}$ alloys. The alloy without $\mathrm{Fe}$ addition shows an endothermic reaction caused by glass transition beginning at $440 \mathrm{~K}$, followed by three exothermic reactions caused by crystallization with the onset temperature of 464,513 , and $593 \mathrm{~K}$, respectively. The glass transition and three crystallization processes are also observed in the alloys with $\mathrm{Fe}=5$ and 7 at\%. The distinct glass transition and sharp crystallization peaks in the DSC trace is the typical feature in different BMG systems. This confirms the amorphous nature of the three alloys. In the $\mathrm{Fe}=10$ alloy, the endothermic reaction caused by glass transition is very weak, and the total enthalpy of the three crystallization also decreases, but an additional exothermic peak near the melting point of the alloy is observed. For the alloys with $\mathrm{Fe}=15$ and 20 at $\%$, the three crystallization peaks and glass transition process disappear in the DSC plots. Instead, a very broad and weak exothermic peak from 630 to $750 \mathrm{~K}$ followed by a sharp exothermic peak closed to the melting point is observed. This DSC feature is similar to that of the $\mathrm{Nd}(\mathrm{Pr})$-based BMG with high Fe content (e.g. $\mathrm{Nd}_{60} \mathrm{Al}_{10} \mathrm{Fe}_{30}$, and $\mathrm{Nd}_{60}$ $\mathrm{Al}_{10} \mathrm{Fe}_{20} \mathrm{Co}_{10}$, etc.), which possesses a highly relaxed amorphous structure or a composite structure consisted of amorphous and clusters (or nanocrystals) [12-16].

HRTEM images of the as-cast $\mathrm{Fe}=0$ and 20 alloys are shown in Fig. 3. The Fe-free $\mathrm{Nd}_{60} \mathrm{Al}_{10} \mathrm{Ni}_{10} \mathrm{Cu}_{20}$ alloy
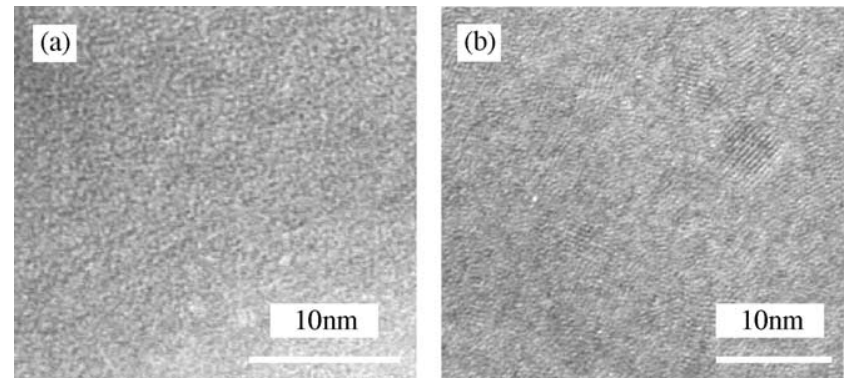

Fig. 3. HRTEM of $\mathrm{Nd}_{60} \mathrm{Al}_{10} \mathrm{Ni}_{10} \mathrm{Cu}_{20}$ alloy (a); and $\mathrm{Nd}_{60} \mathrm{Al}_{10} \mathrm{Ni}_{10} \mathrm{Fe}_{20}$ alloy (b). 
exhibits a uniform amorphous microstructure. In contrast, the high $\mathrm{Fe}$ content alloy shows a composite structure, i.e. nanocrystals or clusters with the size of about $5 \mathrm{~nm}$ randomly dispersed in the amorphous matrix. This microstructure feature agrees with the results of others Nd-based BMGs with high Fe content [12,14].

In the present work, nanoindentation was used to study the plastic deformation behavior of $\mathrm{Nd}_{60} \mathrm{Al}_{10} \mathrm{Ni}_{10} \mathrm{Cu}_{20-x} \mathrm{Fe}_{x}$ BMGs with different microstructure. Typical load-displacement $(P-h)$ curves for nanoindentations on each of the alloys are presented in Fig. 4(a), where the BMGs were indented to the depth of $500 \mathrm{~nm}$ using continuous stiffness option at a constant displacement rate of $5 \mathrm{~nm} / \mathrm{s}$. In this figure, the origin of each curve has been displaced so that multiple curves can be accommodated on the each graph, and only the loading portions of the $P-h$ curves are shown for clarity. As shown in Fig. 4(a), the shape of the $P-h$ curves of $\mathrm{Nd}_{60} \mathrm{Al}_{10} \mathrm{Ni}_{10} \mathrm{Cu}_{20-} \mathrm{Fe}_{x}$ BMGs can be divided in two groups: the low $\mathrm{Fe}$ content alloys $(\mathrm{Fe}=0,5$, and 7$)$ exhibit a lower slope indicating a lower hardness, and the high $\mathrm{Fe}$ content alloys $(\mathrm{Fe}=10,15$, and 20) exhibit a higher slope indicating a higher hardness. It is also noted that $P-h$
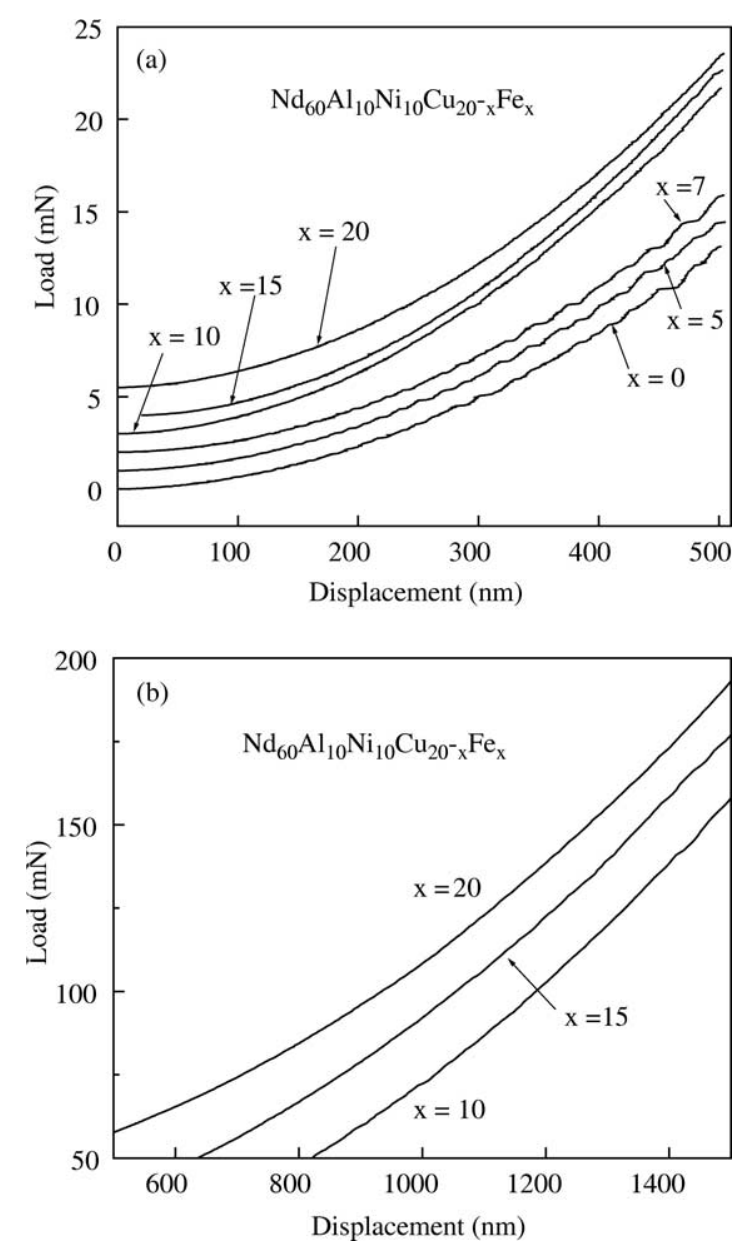

Fig. 4. Typical load-displacement $(P-h)$ curved measurement on the loading portion of nanoindentation to the depth of $500 \mathrm{~nm}$ (a); and $3000 \mathrm{~nm}$ (b). plots of the low Fe content alloys exhibit several displacement discontinuity or pop-in marks indicating a sudden penetration of the tip into the sample. The starting depth for the appearance of the distinct serrated flow gradually increases from 180 to $230 \mathrm{~nm}$ with increasing Fe content from 0 to $7 \%$. For the high Fe alloys, the serrated flow feature is very weak in the $\mathrm{Fe}=10$ alloy, and the starting depth of serration is about $295 \mathrm{~nm}$. The $\mathrm{Fe}=15$ and 20 alloys show very smooth parabolic $P-h$ curve without any serration can be observed up to $500 \mathrm{~nm}$. All of the four kinds of nanoindentation measurements show the same tendency.

Fig. 4(b) shows enlarged $P-h$ curves for indentation depth of $3000 \mathrm{~nm}$ of the high $\mathrm{Fe}$ alloys $(\mathrm{Fe}=10,15$, and $20)$. It can be found that the high Fe alloys also shows serrated flow at a lager penetration depth. The starting depth for the $\mathrm{Fe}=15$ alloys is about $1100 \mathrm{~nm}$, and the value for $\mathrm{Fe}=20$ alloy is about $1400 \mathrm{~nm}$. Moreover, the high Fe alloys exhibits a smoother displacement bursts than the low Fe alloys.

The complete $P-h$ plots including unloading curves are shown in Fig. 5. Only the results of Fe-free and $\mathrm{Fe}=20$ alloys are shown for clarity. The shape of $P-h$ curves of $\mathrm{Fe}=5$ and 7 alloys is quite similar to that of the Fe-free alloy, and the shape of $\mathrm{Fe}=10$ and 15 alloys is quite similar to that of $\mathrm{Fe}=20$ alloy. The higher load and the higher slope of the unloading curve of high Fe alloy indicate a higher hardness and elastic modulus. Hardness and elastic modulus profiles as a function of indentation depth for the $\mathrm{Fe}$-free and $\mathrm{Fe}=20$ alloys are shown in Fig. 6. The average hardness and modulus over the defined range of $\mathrm{Fe}$-free alloy is 3.25 , and $48.4 \mathrm{GPa}$, respectively. While those of the $\mathrm{Fe}=20$ alloy is 4.42 , and $60.1 \mathrm{GPa}$, respectively. After removal of the indenter tip, the plastic deformation of $\mathrm{Fe}$-free alloy is about $393 \mathrm{~nm}$, while $373 \mathrm{~nm}$ for the $\mathrm{Fe}=20$ alloy. This means the low Fe alloys undergo a larger plastic deformation during nanoindentation experiments.

Fig. 7 shows the typical surface deformation features of $\mathrm{Fe}$-free and $\mathrm{Fe}=15$ alloys obtained after nanoindentation at the depth of $3000 \mathrm{~nm}$ examined by optical and AFM

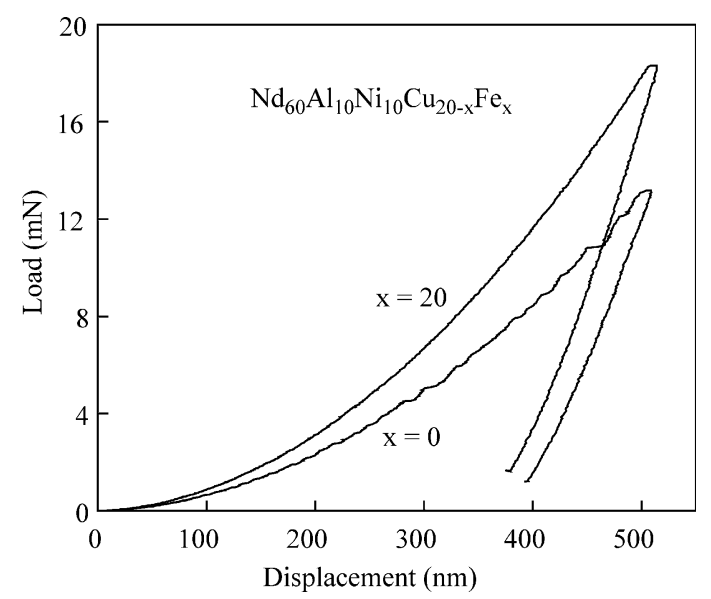

Fig. 5. Complete $P-h$ plots including unloading curves of $\mathrm{Fe}=0$ and 20 alloys. 


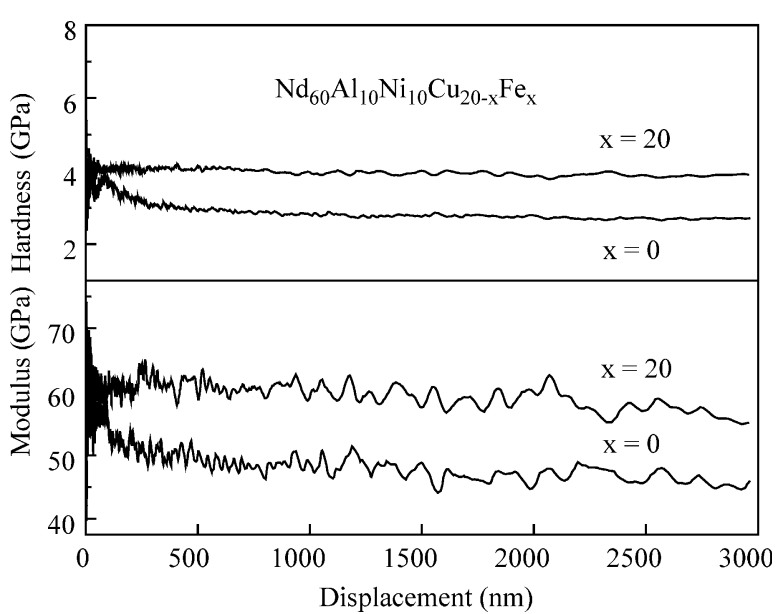

Fig. 6. Hardness and elastic modulus profiles as a function of indentation depth for the $\mathrm{Nd}_{60} \mathrm{Al}_{10} \mathrm{Ni}_{10} \mathrm{Cu}_{20-x} \mathrm{Fe}_{x}$ alloys, (a) $x=0$; (b) $x=20$.
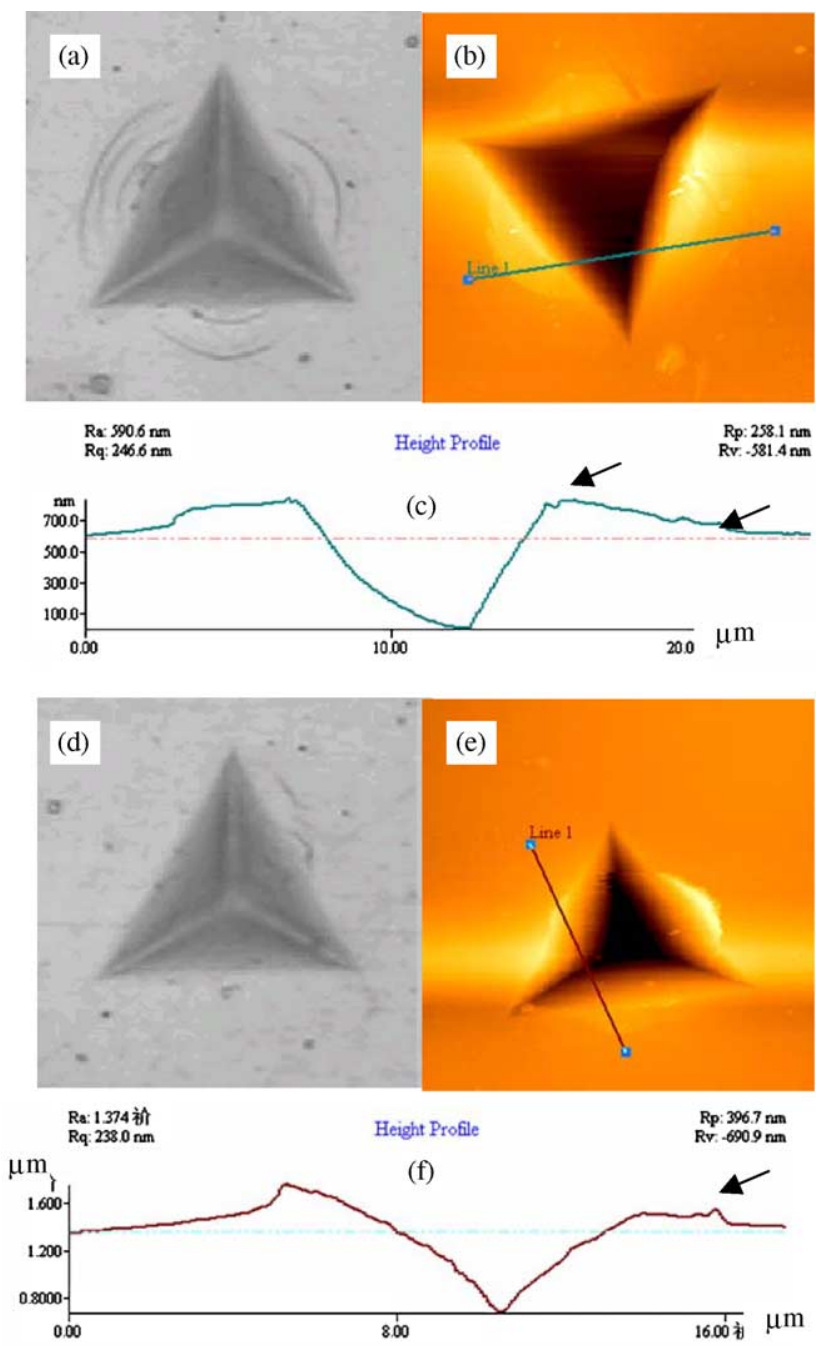

Fig. 7. Typical surface deformation features obtained from indents. Fe-free alloy: (a) optical image; (b) AFM image; (c) corresponding section analysis; $\mathrm{Fe}=15$ alloys; (d) optical image; (e) AFM image, and (f) corresponding section analysis. method. Circular patterns are observed around the indent for Fe-free alloy (Fig. 7(a)). AFM topographic image and section analysis show (Fig. 7(b) and (c)) that the circular configurations constitute a pile-up as indicated by arrows. They represent overlapping layers of displaced material that flow upwards and away from the depth of the indent. Very few circular patterns are observed in $\mathrm{Fe}=15$ alloy (Fig. 7(d)), and the significant decrease of the height and length of the pile-up is revealed (Fig. 7(e) and (f)).

Serrated flow phenomenon manifested as a stepped load-displacement curve punctuated by discrete bursts of plasticity during nanoindentation was already found in Pd-, $\mathrm{Zr}$ - and La-based BMGs [7-10]. The discrete pop-in events correspond to the activation of individual shear bands. The present experimental data indicate that the low $\mathrm{Fe}$ content $\mathrm{Nd}_{60} \mathrm{Al}_{10} \mathrm{Ni}_{10} \mathrm{Cu}_{20-x} \mathrm{Fe}_{x}$ BMG with a homogeneous amorphous structure also exhibit a conspicuous serrated flow feature during the loading process of nanoindentation. High Fe content alloys possess a composite microstructure consisting of amorphous phase plus nanocrystals or clusters, and the medium Fe alloys is presumed to possess a highly relaxed amorphous structure with highly developed short range ordered structure. A larger plastic deformation is observed in low Fe alloys, which may be related to the form of numerous strain serrations. Nieh et al. has revealed that the serrated flow is strongly dependent on the indentation strain rate, with lower rates promoting more prominent serrations or displacement bursts in BMGs [10]. In the present study, it is suggested that the serrated flow is remarkable affected by the microstructure, e.g. local free volume, as well as short- or medium-range ordering (either geometric or chemical) of the local constitutes. It exhibits that the relaxed structure and amorphous-cluster (or nanocrystal) composite structure in high $\mathrm{Fe}$ alloys have a high resistance against the plastic deformation. As shown in Figs. 3 and 5, the increase of $\mathrm{Fe}$ content gradually retards the onset depth of the appearance of serrated flow, and in the high Fe content alloys the serration start at a very large depth $(1100 \sim 1400 \mathrm{~nm})$. In other words, the serrated flow gradually changes from the discrete to continuous plastic deformation with increasing $\mathrm{Fe}$ content. Greer et al. has studied the effect of dispersed nanocrystals in the amorphous matrix on the serrated flow behavior of rapidly solidified $\mathrm{Fe}-\mathrm{Ni}-(\mathrm{Zr})-\mathrm{B}$ ribbons under nanoindentation [17]. It is proposed that crystals larger than the shear-band thickness can interfere with normal shearband operation and suppress shear-banding, while, crystals smaller than shear-band thickness leave shear-band operation unaffected. This critical effect of crystal size on the serrated flow behavior is also observed in the present NdAlNiCuFe BMGs, although the shear-band thickness under this condition is still not clear. The higher free volume in the unrelaxed low $\mathrm{Fe}$ alloys gives rise to the propagation of a single shear band, which rapidly accommodate the applied strain, leading to a strain burst. In contrast, in the highly relaxed high $\mathrm{Fe}$ alloys with larger nanocrystal 

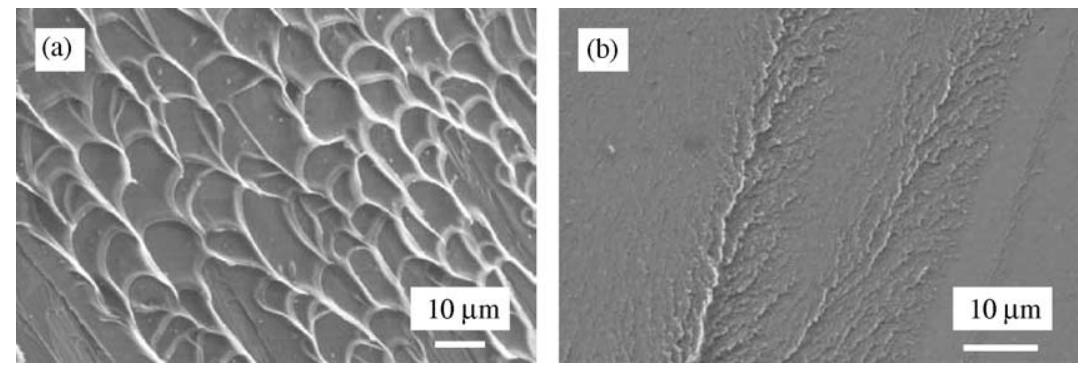

Fig. 8. The fracture surfaces of the $\mathrm{Fe}=0(\mathrm{a})$; and $\mathrm{Fe}=20$ (b) alloys after uniaxial compression tests with an initial strain rate of $1.4 \times 10^{-4} \mathrm{~s}^{-1}$.

size $(>5 \mathrm{~nm})$, the propagation of a single shear band is obstructed by the nanocrystals in a very limited length scale, and many shear bands would be required at every instant in order to accommodate the applied strain.

Fig. 8 exhibits the fracture surfaces of the Fe free and $\mathrm{Fe}=20$ alloys after uniaxial compression tests with an initial strain rate of $1.4 \times 10^{-4} \mathrm{~s}^{-1}$. The vein-like patterns in the fracture surface of Fe-free alloy confirm a remarkable plastic flow before failure (Fig. 8(a)). While, for the high Fe alloy, the flow feature is not distinct and multiple shear bands are seem to be initiated.

\section{Summary}

In the present study, $\mathrm{Nd}_{60} \mathrm{Al}_{10} \mathrm{Ni}_{10} \mathrm{Cu}_{20-x} \mathrm{Fe}_{x}(x=0,5$, $7,10,15,20)$ amorphous-like alloys were prepared in the form of $3 \mathrm{~mm}$-diameter rod. The increase of $\mathrm{Fe}$ content changes its structure from homogeneous amorphous phase to a composite microstructure, which consists of amorphous matrix plus clusters or nanocrystals. Pronounced flow serrations in the $P-h$ plots of nanoindentation are observed in the low Fe content alloys. The increase of Fe content retards the occurrence of the serration flow obviously. The high Fe content alloys, with a highly relaxed structure, have a higher hardness and elastic modulus, as well as a higher resistance against the plastic deformation.

\section{Acknowledgements}

The authors would like to acknowledge the financial support provided by National Nature Science Foundation of China (Grant No. 50101012) and the Knowledge Innovation Program of Chinese Academy of Sciences.

\section{References}

[1] Wright WJ, Saha R, Nix WD. Mater Trans JIM 2001;42:642.

[2] Pekarskaya E, Kim CP, Johnson WL. J Mater Res 2001;16:2513.

[3] Inoue A. Acta Mater 2000;48:279.

[4] Flores KM, Dauskart RH. Acta Mater 2001;49:2527.

[5] Zhang ZF, He G, Eckert J, Schultz L. Phys Rev Lett 2003;91:045505.

[6] Hufnagel TC, Fan C, Ott RT, Li J. Brennan. Intermetallics 2002;10: 1163.

[7] Schuh CA, Nieh TG. Acta Mater 2003;51:87.

[8] Wang JG, Choi BW, Nieh TG, Liu CT. J Mater Res 2000;15:798.

[9] Benameur T, Hajlaoui K, Yavari AR, Inoue A, Rezgui B. Mater Trans 2002;43:2617.

[10] Nieh TG, Schuh C, Wadsworth J, Li Y. Intermetallics 2002;10:1177.

[11] Oliver WC, Pharr GM. J Mater Res 1992;7:1564.

[12] Inoue A, Takeuchi A, Zhang T. Metall Mater Trans 1998;29A:1779.

[13] Li Y, Ng SC, Lu ZP, Feng YP, Lu K. Phil Mag Lett 1998;78:213.

[14] Xia L, Wei BC, Zhang Z, Pan MX, Dong YD, Wang WH. J Phys D: Appl Phys 2003;36:1.

[15] Wei BC, Löser W, Xia L, Roth S, Pan MX, Wang WH, Eckert J. Acta Mater 2002;50:4357.

[16] Zhang Z, Xia L, Wang RJ, Wei BC, Pan MX, Wang WH. Appl Phys Lett 2002;81:4371.

[17] Greer AL, Walker IT. Mater Sci Forum 2002;386-388:77. 